\title{
A DFT study on the interaction of doped carbon nanotubes with H2S, SO2 and thiophene
}

\author{
Hossein Tavakol $^{1}$ and Hamed Haghshenas ${ }^{2}$ \\ ${ }^{1}$ Isfahan University of Technology \\ ${ }^{2}$ Shahrekord University
}

November 17, 2020

\begin{abstract}
The interactions of simple and $\mathrm{Al}, \mathrm{B}, \mathrm{N}, \mathrm{S}, \mathrm{P}$ and Si-doped carbon nanotubes with three sulfur-containing molecules (H2S, $\mathrm{SO} 2$ and thiophene) have been investigated to assess their adsorption potencies and sensor abilities. DFT calculations were used to calculate the adsorption energies and NBO parameters. Besides, Population analyses were performed to calculate the energy gaps and reactivity parameters and to obtain DOS plots. The results showed an exothermic interaction of $\mathrm{H} 2 \mathrm{~S}$, SO2 and thiophene with simple and doped CNTs while the maximum negative adsorption energies were belonged to $\mathrm{Al}$ and $\mathrm{B}$ containing complexes. Furthermore, evaluation of second order perturbation energies (obtained from NBO calculations) confirmed that the highest energies were related to $\mathrm{B}$ and $\mathrm{Al}$ containing intramolecular interactions. The results revealed the favourability of adsorption of SO2 by nanotubes ( $\mathrm{B}$ and $\mathrm{Al}$ doped carbon nanotubes, in particular), in comparing with the other examined adsorbates.
\end{abstract}

\section{Hosted file}

manuscript.pdf available at https://authorea.com/users/288390/articles/493402-a-dft-studyon-the-interaction-of-doped-carbon-nanotubes-with-h2s-so2-and-thiophene 